- anti-Ku antibody is not specific of a connective tissu disease and can also be observed in patients without any autoimmune disease $\left(n^{\circ} 7\right)$.

- In addition to previous described association, anti-Ku antibody can also be present in Wegener granulomatosis and idiopathic Raynaud's phenomen.

- Two of our patients had an evaluative cancer ( ${ }^{\circ} 5$ and 8$)$ and one $\left(\mathrm{n}^{\circ} 7\right)$ presented a stomach neoplasm 3 years before the detection of anti-Ku antibody. This finding needs further investigations to assess if anti-Ku antibody can be associated with or predictive of a neoplasm.

\section{THU0065 CLINICAL SIGNIFICANCE OF ANTI-ASPARAGINYL TRNA SYNTHETASE AUTOANTIBODIES}

${ }^{1}$ M Hirakata, ${ }^{1}$ A Suwa, ${ }^{1} \mathrm{~T}$ Nojima, ${ }^{1} \mathrm{M}$ Suzuki, ${ }^{2} \mathrm{~S}$ Nagai, ${ }^{3} \mathrm{~T}$ Mimori, ${ }^{4} \mathrm{IN}$ Targoff. ${ }^{1}$ Internal Medicine, Keio University School of Medicine, Tokyo; ${ }^{2}$ Respiratory Medicine; ${ }^{3}$ Clinical Immunology, Kyoto University, Kyoto, Japan; ${ }^{4}$ Medicine, University of Oklahoma, Oklahoma City, USA

\subsection{6/annrheumdis-2001.909}

Background Autoantibodies to 5 of the aminoacyl tRNA synthetases (those for histidine, threonine, alanine, isoleucine and glycine) have been described, and each is associated with a similar syndrome of myositis (PM or DM) with interstitial lung disease (ILD), arthritis, and other features. ${ }^{1}$ We have identified novel autoantibodies to asparaginyl tRNA synthetase (AsnRS), ${ }^{2}$ but the clinical significance of this sixth anti-synthetase antibody has not been well-defined.

Objectives The aim of the present study was to identify patients with anti-AsnRS and elucidate the clinical and immunogenetic features of this sixth anti-synthetase autoantibodies.

Methods Sera from more than 2,500 patients with connective tissue disease including myositis and ILD in collaborating centres, and control sera were examined for anti-AsnRS antibodies by immunoprecipitation. Positive sera and controls were tested for the ability to inhibit AsnRS by preincubation of the enzyme source with the serum. The HLA-class II (DRB1, DQA1, DQB1, DPB1) alleles were identified from RFLP of PCR-amplified genomic DNA. The concentration of KL-6 (a new marker for ILD) in serum was determined by a specific ELISA. ${ }^{3}$

Results Anti-KS antibodies were identified in the sera of 8 patients (5 Japanese, 1 U. S., 1 German, 1 Korean), by immunoprecipitation of the same distinctive set of tRNAs and protein that differed from those precipitated by the other 5 anti-synthetases, and showed specific inhibition of AsnRS activity. Two of these patients had DM, but seven of $8(88 \%)$ had ILD. Four $(50 \%)$ had arthritis, and one had Raynaud phenomenon. This anti-synthetase was very rare among myositis patients, found in $<0.2 \%$ of U. S. myositis patients, and $0 \%$ of Japanese myositis patients, but was found in 3\% of Japanese ILD patients. Thus, most patients with anti-AsnRS antibodies had chronic ILD with or without features of connective tissue disease. Furthermore, four of 5 patients in whom KL-6 levels were measured, showed markedly elevated levels (mean level $919.8 \mathrm{U} / \mathrm{ml}$; normal < 500 $\mathrm{U} / \mathrm{ml})$. Interestingly, all four Japanese patients tested had DR 2 (DRB1*1501/1502), compared to 33\% of healthy controls.

Conclusion These results indicate that anti-AsnRS antibodies, like anti-PL-12 (alanyl tRNA synthetase) antibodies, have a stronger association with ILD than with myositis, and may be associated with the DR2 phenotype.
2 Hirakata M, et al. J Immunol. 1999;162:2315-20

3 Nakajima $\mathrm{H}$, et al. J Rheumatol. 2000;27:1164-70

\section{THU0066 AUTOANTIGENIC EPITOPES TARGETED BY AUTOANTIBODIES TO RNA HELICASE A IN SYSTEMIC LUPUS ERYTHEMATOSUS}

${ }^{1}$ A Suwa, ${ }^{1} \mathrm{M}$ Hirakata, ${ }^{1} \mathrm{~T}$ Nojima, ${ }^{1} \mathrm{~S}$ Satoh, ${ }^{2} \mathrm{~T}$ Nakajima, ${ }^{3} \mathrm{~T}$ Mimori. ${ }^{1}$ Internal Medicine, Keio University, Tokyo; ${ }^{2}$ Medical Research, St. Marianna Medical University, Kawasaki; ${ }^{3}$ Clinical Immunology, Kyoto University, Kyoto, Japan

\subsection{6/annrheumdis-2001.910}

Background We have previously described new autoantibodies which recognise the $140 \mathrm{kDa}$ polypeptide (p140) in a patient serum with SLE. Recently we have demonstrated that these antibodies are targeting RNA helicase A (RHA) which plays a pivotal role in nuclear events.

Objectives To investigate the target epitopes recognised by autoantibodies to RHA.

Methods Sera from 561 patients with systemic rheumatic disease (287 SLE, 71 SSc, 67 PM/DM, 58 RA, 54 MCTD/overlap, 18 Sjogren syndrome and 6 vasculitis syndrome), and 80 normal humans were screened by immunoprecipitation assay using [35S]-Met-labelled HeLa cell extracts as antigen. In some experiments, [32P]-labelled HeLa cells were used to analyse nucleic acid components. To determine the antigenic epitopes on RHA, restriction fragments of cDNA encoding D1 (amino acids 1-250) containing double-stranded RNA binding domain, D2 (230-650) containing a DEAH box motif, D3 (630-1,020), and D4 $(1,000-$ 1,279 ) containing a glycine-rich region were subcloned into pGEX-2TK vector and expressed in E. coli. The resulting fusion proteins (PD1, PD2, PD3, and PD4) were detected with patient sera.

Results We have found 10 sera which immunoprecipitated a 140 $\mathrm{kDa}$ polypeptide from HeLa cell extracts in SLE patients with nephritis. When the precipitated polypeptides were used as antigen in immunoblotting, p140 was recognised by rabbit antisera against RHA. Thus, we have confirmed that all 10 sera contain autoantibodies to RHA. Moreover, it was noted that anti-RHA sera coprecipitated high molecular weight nucleic acids from [32P]-labelled HeLa cell extracts. When cell extracts were treated with RNase, these sera were unable to coprecipitate high molecular weight nucleic acids, indicating that nucleic acid components were RNAs. Under various salt conditions, anti-RHA antibodies were able to coprecipitate nucleic acid components at salt conditions lower than $0.35 \mathrm{M} \mathrm{NaCl}$. These results suggested that RHA is interacting with hn-RNA or mRNA. In immunoblotting using the fusion proteins (PD1, PD2, PD3, and PD4), all 10 anti-RHA positive sera strongly recognised PD4. Eight and 9 out of 10 sera recognised PD1 and PD3, respectively, but intensity of binding was variable among different sera. In contrast, none of sera reacted with PD2.

Conclusion Autoantibodies to RHA were identified exclusively in patients with lupus nephritis. The universal epitope was present on the carboxyl-terminal domain of RHA. The reactive patterns of antibodies against multiple antigenic determinants detected here were consistent with the hypothesis that relatively native RHA molecules directly elicit autoantibodies in selected patients.

\title{
REFERENCES
}

1 Targoff IN. Rheum Dis Clin North Am. 1994;20:857-80 